\title{
BMJ Open Temporal trends in antithrombotic treatment of real-world UK patients with newly diagnosed atrial fibrillation: findings from the GARFIELD-AF registry
}

Patricia N Apenteng, ${ }^{1}$ Haiyan Gao, ${ }^{2}$ FD Richard Hobbs, ${ }^{3}$ David A Fitzmaurice, ${ }^{1}$ on behalf of UK GARFIELD-AF Investigators and GARFIELD-AF Steering Committee

To cite: Apenteng PN, Gao H, Hobbs FDR, et al. Temporal trends in antithrombotic treatment of real-world UK patients with newly diagnosed atrial fibrillation: findings from the GARFIELD$\mathrm{AF}$ registry. BMJ Open 2018;8:e18905. doi:10.1136/ bmjopen-2017-018905

- Prepublication history and additional material for this paper are available online. To view these files, please visit the journal online (http://dx.doi. org/10.1136/bmjopen-2017018905).

Received 1 August 2017 Revised 25 September 2017 Accepted 3 November 2017

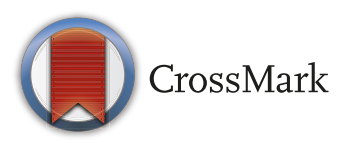

${ }^{1}$ Clinical Trials Unit, Warwick Medical School, University of Warwick, Coventry, UK

${ }^{2}$ Thrombosis Research Institute, London, UK

${ }^{3}$ Nuffield Department of Primary Care Health Sciences, University of Oxford, Oxford, UK

Correspondence to Mrs Patricia N Apenteng; p.apenteng@warwick.ac.uk

\section{ABSTRACT}

Objective To investigate evolving patterns in antithrombotic treatment in UK patients with newly diagnosed non-valvular atrial fibrillation (AF).

Design Prospective, multicentre, international registry.

Setting 186 primary care practices in the UK.

Participants 3482 participants prospectively enrolled in four sequential cohorts (cohort 2 (C2) $n=830$, diagnosed September 2011 to April 2013; cohort 3 (C3) $n=902$, diagnosed April 2013 to June 2014; cohort 4 (C4) n=850, diagnosed July 2014 to June 2015; cohort 5 (C5) $n=900$, diagnosed June 2015 to July 2016). Participants had newly diagnosed non-valvular AF and at least one risk factor for stroke, were aged $\geq 18$, and provided informed consent.

Main outcome measures Antithrombotic treatment initiated at diagnosis, overall and according to stroke and bleeding risks. Stroke risk was retrospectively calculated using $\mathrm{CHA}_{2} \mathrm{DS}_{2}$-VASc (cardiac failure, hypertension, age $\geq 75$ (doubled), diabetes, stroke (doubled)-vascular disease, age 65-74 and sex category (female)) and bleeding risk using HAS-BLED (hypertension, abnormal renal/liver function (1 point each), stroke, bleeding history or predisposition, elderly (>65), drugs/alcohol concomitantly (1 point each)).

Results $42.7 \%$ were women and the mean age was 74.5 years. The median $\mathrm{CHA}_{2} \mathrm{DS}_{2}$-VASc score was 3 in all cohorts and the median HAS-BLED score was 2 in all cohorts. There was a statistically significant increase in the use of anticoagulant therapy from C2 to C5 (C2 $54.7 \%$, C3 60.3\%, C4 73.1\%, C5 73.9\%; P value for trend $<0.0001)$. The increase in the use of anticoagulant was mainly in patients with $\mathrm{CHA}_{2} \mathrm{DS}_{2}-\mathrm{VASc} \geq 2$. The use of vitamin $\mathrm{K}$ antagonists (VKAs) \pm antiplatelet (AP) drugs decreased from C2 to C5 (C2 53.3\%, C3 52.1\%, C4 50.3\%, C5 $30.6 \%$ ), while the use of non-vitamin $\mathrm{K}$ antagonist oral anticoagulants (NOACs) \pm AP increased (C2 1.3\%, C3 $8.0 \%$, C4 $22.7 \%$, C5 $43.3 \%$ ). The use of AP only decreased (C2 36.4\%, C3 25.5\%, C4 11.9\%, C5 10.5\%), as did the combination therapy of VKA+AP (C2 13.6\%, C3 11.0\%, C4 $9.6 \%$, C5 5.8\%).

Conclusion There has been a progressive increase in the proportion of patients newly diagnosed with $\mathrm{AF}$ receiving

\section{Strengths and limitations of the study}

- This study describes real-world clinical practice in the UK for treatment initiated at atrial fibrillation (AF) diagnosis in patients with $\mathrm{AF}$ and at least one risk factor for stroke.

- Eligible patients were enrolled prospectively and consecutively without exclusions according to comorbidities or treatment.

- Patients were recruited in primary care in the UK, encompassing patients diagnosed in a comprehensive range of national care settings.

- This study does not include patients without capacity to consent.

guideline-recommended therapy in the UK, potentially driven by the availability of NOACs.

Trial registration number NCT01090362; Pre-results.

\section{INTRODUCTION}

Atrial fibrillation (AF) is a potent risk factor for stroke and mortality; people with $\mathrm{AF}$ have a fivefold increased risk of stroke and a twofold increased risk of death. ${ }^{12}$ AF-related strokes are more serious and are more likely to be fatal or lead to long-term disability than strokes in people without this arrhythmia. ${ }^{3}$ Stroke prevention is therefore a principal goal in the treatment of $\mathrm{AF}^{4}$ and is a major public health priority. ${ }^{5}$ Fortunately, there are effective therapies, with anticoagulation shown to mitigate up to two-thirds of this stroke risk.

Since 2010, changes in treatment guidelines from the European Society of Cardiology and the National Institute for Clinical Excellence (NICE) have widened the criteria for patients with AF that should be considered for antithrombotic therapy and now advocate 
Table 1 Baseline characteristics of patients in cohorts 2 to 5

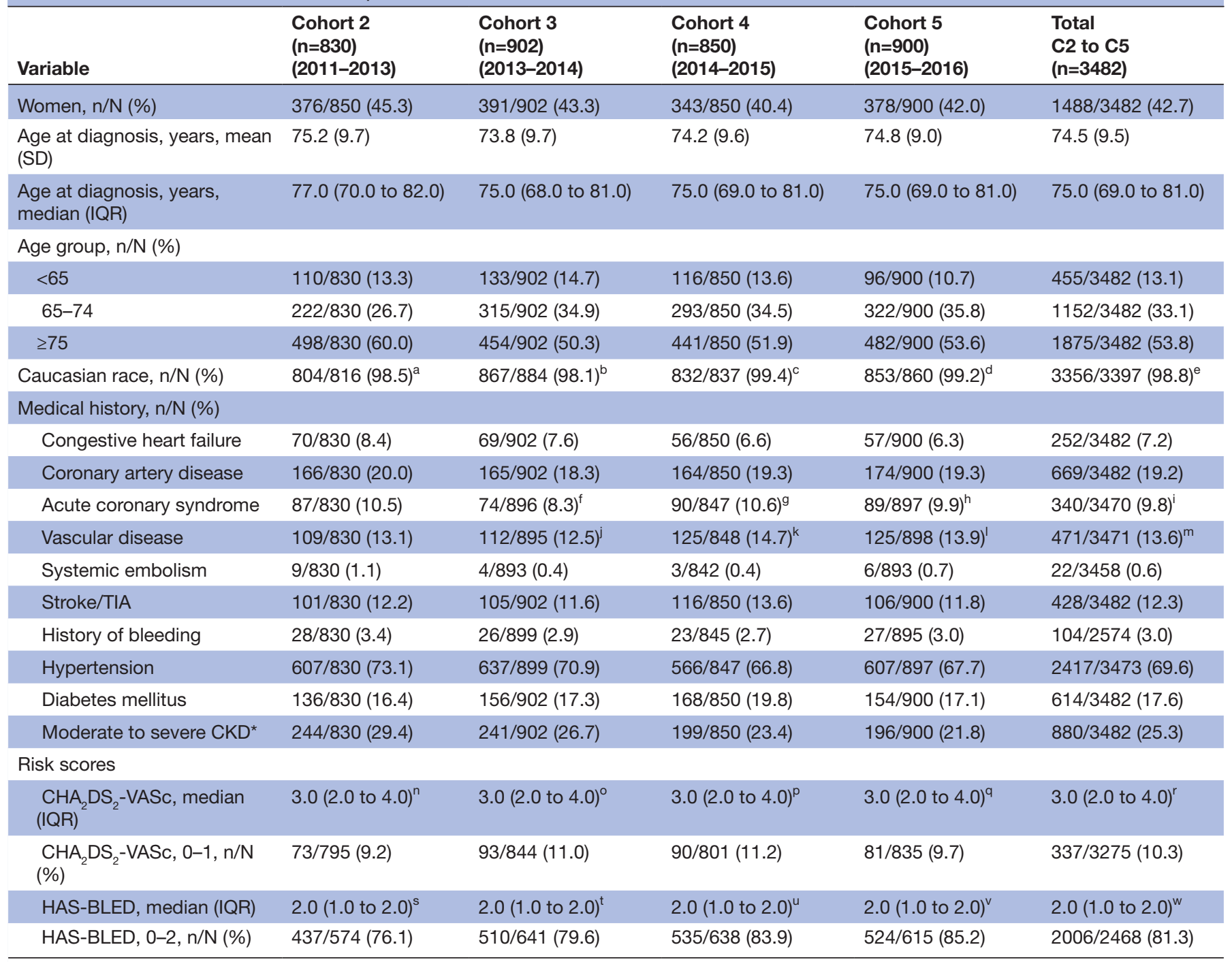

Patients missing: ${ }^{\mathrm{a}} 14,{ }^{\mathrm{b}} 18,{ }^{\mathrm{c}} 13,{ }^{\mathrm{d}} 40,{ }^{\mathrm{e}} 85,{ }^{\mathrm{f}} 6,{ }^{\mathrm{g}} 3,{ }^{\mathrm{h}} 3,{ }^{\mathrm{i}} 12,{ }^{\mathrm{j}} 7,{ }_{2},{ }^{\mathrm{l}} 1, \mathrm{~m}_{11},{ }^{\mathrm{n}} 35,{ }^{\mathrm{o}} 58,{ }^{\mathrm{p}} 49,{ }^{\mathrm{q}} 65,{ }^{\mathrm{r}} 207,{ }^{\mathrm{s}} 256,{ }^{\mathrm{t}} 261,{ }^{\mathrm{u}} 212,{ }^{\mathrm{v}} 285,{ }^{\mathrm{w}} 1014$. ${ }^{*}$ Includes NKF KDOQI stages III-V.

$\mathrm{CHA}_{2} \mathrm{DS}_{2}$-VASc, cardiac failure, hypertension, age $\geq 75$ (doubled), diabetes, stroke (doubled)-vascular disease, age 65-74 and sex category (female); CKD, chronic kidney disease; HAS-BLED, hypertension, abnormal renal/liver function (1 point each), stroke, bleeding history or predisposition, elderly (>65), drugs/alcohol concomitantly (one point each); NKF KDOQI, National Kidney Foundation's Kidney Disease Outcomes Quality Initiative; TIA, transient ischaemic attack.

anticoagulants (ACs) as the only appropriate antithrombotic therapy in patients with $\mathrm{AF}^{45}$ ACs include vitamin $\mathrm{K}$ antagonists (VKAs; typically warfarin) and, recently, non-VKA oral anticoagulants (NOACs), comprising factor $\mathrm{Xa}$ inhibitors and direct thrombin inhibitors. Whereas the only anticoagulant previously recommended was warfarin, the updated AF guidelines from NICE include recommendations for NOACs for patients with non-valvular AF.

In 2014, NICE updated its guidelines on the management of AF, recommending the $\mathrm{CHA}_{2} \mathrm{DS}_{2}$-VASc (cardiac failure, hypertension, age $\geq 75$ (doubled), diabetes, stroke (doubled)-vascular disease, age 65-74 and sex category (female)) stroke risk tool for assessing stroke risk in patients with $\mathrm{AF}$ and further recommending anticoagulation therapy for patients at high risk $\left(\mathrm{CHA}_{2} \mathrm{DS}_{2}-\mathrm{VASc} \geq 2\right)$, a consideration of anticoagulant therapy for patients at moderate risk $\left(\mathrm{CHA}_{2} \mathrm{DS}_{2}-\mathrm{VASc}=1\right)$ and no anticoagulant or antiplatelet (AP) treatment for patients at low risk (defined as $\mathrm{CHA}_{2} \mathrm{DS}_{2}-\mathrm{VASc}=0$ for men and $\mathrm{CHA}_{2} \mathrm{DS}_{2}$ $\mathrm{VASc}=1$ for women). ${ }^{5}$ In addition, the emergence of NOACs in the UK since 2012 has provided a wider range of AC options, particularly for patients for whom warfarin may not be appropriate. The change in guidelines coupled with the emergence of NOACs has the potential to transform clinical practice; however, the impact on the use of ACs in patients with AF in the UK is unclear.

More than 46000 new cases of AF are diagnosed in the UK every year. Many studies have reported a longstanding problem of undertreatment with ACs of patients at high risk of stroke ${ }^{67}$; UK studies in the last decade also report suboptimal treatment, ${ }^{8-11}$ though there is limited 
evidence of AF management since the introduction of NOACs. Little is known about the contemporary realworld management of patients newly diagnosed with $\mathrm{AF}$ who are perceived to be at risk of stroke by their physicians. The Global Anticoagulant Registry in the FIELDAtrial Fibrillation (GARFIELD-AF) aims to determine real-life treatment patterns and clinical outcomes of patients with newly diagnosed non-valvular $\mathrm{AF}$ and at least one investigator-determined risk factor for stroke. ${ }^{12} 13$ This paper investigates the evolving patterns of antithrombotic treatment of UK patients enrolled in the GARFIELD-AF registry from September 2011 to July 2016.

\section{METHODS}

\section{Study design}

GARFIELD-AF is an ongoing, prospective, non-interventional, international registry of adults ( $\geq 18$ years) diagnosed with AF. Patients were recruited into five independent cohorts; the first cohort also included a validation cohort of retrospective patients.

\section{Participants}

Inclusion criteria for the prospective cohort comprised a new diagnosis of non-valvular AF of up to 6 weeks prior to entry into the registry and an investigator-determined risk factor for stroke. Eligible patients were recruited consecutively at participating sites in order to prevent selection bias. The retrospective cohort comprised patients diagnosed 6-24 months before enrolment. Patients are followed up for a minimum of 2 years. Patients with transient $\mathrm{AF}$, secondary to a reversible cause, and patients for whom follow-up was not possible were excluded from the registry. Full methods of the GARFIELD-AF registry have been previously reported. ${ }^{12} 13$

This paper reports baseline characteristics and treatment patterns in UK participants enrolled into cohorts 2 to 5; participants enrolled into cohort 1 were excluded as it consisted predominantly of a retrospective validation cohort.

\section{Setting}

Enrolment of UK patients into cohorts 2 to 5 was undertaken between September 2011 and July 2016 at 186 general practices (GPs) across the UK (161 in England, 8 in Wales, 8 in Northern Ireland and 9 in Scotland). The necessary regulatory approvals were obtained prior to recruitment, and all patients provided written informed consent prior to enrolment into the registry. The standard national diagnostic criteria for AF apply for GARFIELD-AF, and for the UK this was by electrocardiographic confirmation.

\section{Data sources}

Data collected at baseline comprised demographics, body mass index, type of AF, care setting of diagnosis, treatment strategy initiated at diagnosis, reason for treatment decision and medical history. Data were collected through review of medical records by trained site staff using an electronic case report form.

Stroke risk was calculated retrospectively using $\mathrm{CHA}_{2} \mathrm{DS}_{2}$-VASc score-based variables: heart failure, hypertension, age $\geq 75$ years and $65-74$ years, diabetes mellitus, prior stroke or transient ischaemic attack (TIA), left ventricular ejection fraction $<40 \%$, prior thromboembolism, vascular disease and female gender. HAS-BLED scores were calculated retrospectively using the variables hypertension, abnormal renal/liver function, stroke, bleeding history or predisposition, elderly $(>65)$ and drugs/alcohol concomitantly.

Data for the analysis in this report were extracted from the study database on 28 July 2016.

\section{Definitions}

ACs include VKAs and NOACs. NOACs include oral direct factor Xa inhibitors and oral direct thrombin inhibitors.

Vascular disease was defined as peripheral artery disease and/or coronary artery disease (CAD) with a history of acute coronary syndromes. Hypertension was defined as a documented history of hypertension or blood pressure $>140 / 90 \mathrm{~mm} \mathrm{Hg}$. Chronic kidney disease (CKD) was classified according to the National Kidney Foundation's Kidney Disease Outcomes Quality Initiative (NKF KDOQI) guidelines ${ }^{14}$ : moderate to severe includes stages III to V; none or mild includes all other patients.

\section{Statistical analysis}

Patient characteristics and medical history are described by cohort. Continuous variables are expressed as number of patients and mean $\pm \mathrm{SD}$ and or median and IQR. Categorical variables are expressed as frequencies and percentages. Treatment patterns were analysed by cohort, and by cohort and $\mathrm{CHA}_{2} \mathrm{DS}_{2}-\mathrm{VASc}$ or HAS-BLED. Trends were assessed using an extension of the Wilcoxon rank-sum test.

Logistic regression models were used to assess the risk factors associated with the prescribing of NOACs (vs VKA). The following risk factors were included in the model: gender, age group, race, smoking, congestive heart failure, hypertension, diabetes, $\mathrm{CAD}$, vascular disease, dementia, moderate to severe CKD, non-steroidal anti-inflammatory drug (NSAID) usage, history of bleeding, previous stroke/TIA/systemic embolism (SE) and cohort. ORs with $95 \%$ CIs were estimated to describe the associations of the risk factors and prescribing of NOACs versus VKA, as well as AP and no treatment (No ACs) versus ACs.

Multiple Imputation by Chained Equations was used to fill in missing values, creating five complete datasets. ${ }^{15} 16$ Logistic regression was performed using the imputed datasets. First-degree interaction between comorbidities and time (cohort) was tested using likelihood ratio tests. Only significant interactions were included in the final model.

Statistical analysis was performed using both SAS software V.9.4 (SAS Institute, Cary, NC, USA) and Stata Statistical Software V.14 (StataCorp, College Station, TX, USA). 


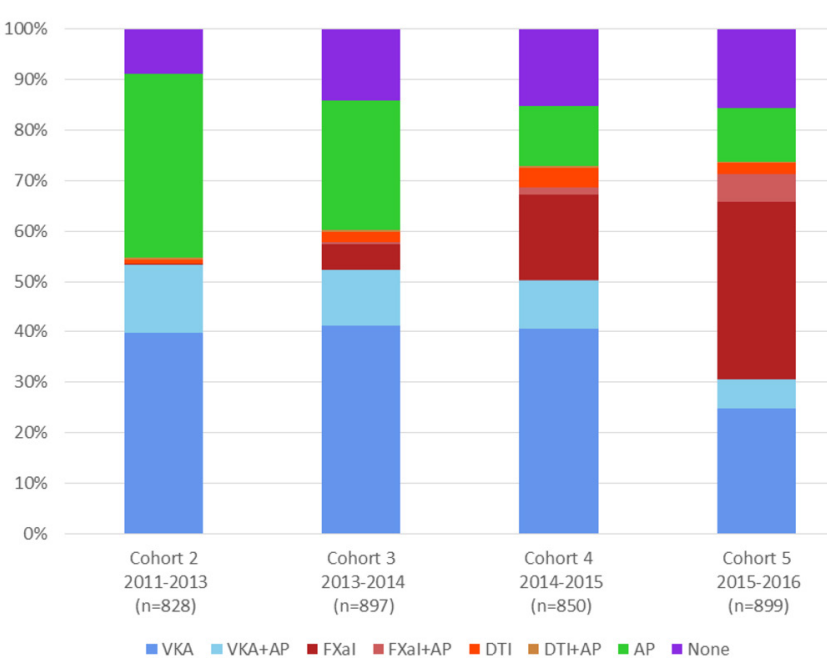

Figure 1 Antithrombotic treatment at diagnosis by cohort. AP, antiplatelet; DTI, direct thrombin inhibitor; FXal, factor Xa inhibitor; VKA, vitamin $\mathrm{K}$ antagonist.

\section{RESULTS}

\section{Patient distribution and characteristics}

In the UK, 3482 patients were enrolled into cohorts 2 to 5 between September 2011 and July 2016: cohort 2 (C2) consisted of 830 patients diagnosed with AF between September 2011 and April 2013, cohort 3 (C3) consisted of 902 patients diagnosed between April 2013 and June 2014, cohort 4 (C4) consisted of 850 patients diagnosed between July 2014 and June 2015, and cohort 5 (C5) consisted of 900 patients diagnosed between June 2015 and July 2016. Overall, $42.7 \%$ of patients were women, mean age (SD) at diagnosis was 74.5 years $(9.5)$ and $89.7 \%$ had a $\mathrm{CHA}_{2} \mathrm{DS}_{2}$-VASc score of $\geq 2$ (table 1 ).

Participants were diagnosed in a broad range of care settings representative of those in the UK: more than half of the patients $(2124 / 3482 ; 61.0 \%)$ were diagnosed in primary care. The remainder were diagnosed in internal (general) medicine $(21.9 \%)$, cardiology $(15.2 \%)$, geriatrics $(1.8 \%)$ and neurology $(0.1 \%)$. Of the 3482 participants, 1370 (39.3\%) had new or unclassified AF, 640 (18.4\%) had paroxysmal AF, $272(7.8 \%)$ had persistent $\mathrm{AF}$ and 1200 (34.5\%) had permanent AF. There were some variations in baseline characteristics across the four cohorts (table 1), though the median $\mathrm{CHA}_{2} \mathrm{DS}_{2}$-VASc and HAS-BLED scores were similar.

\section{Antithrombotic therapy use by cohort}

Figure 1 shows the treatment patterns at diagnosis in each of the four cohorts. The proportion of patients prescribed AC therapy at diagnosis, with or without an AP, increased consistently from C2 to C5 (54.7\%, $60.3 \%, 73.1 \%$ and $73.9 \%$; for trend $<0.0001)$, whereas the use of AP only decreased $(36.4 \%, 25.5 \%, 11.9 \%$ and $10.5 \%)$. At the same time, there was an increase in the proportion of patients receiving NOACs with or without AP from C2 to C5 $(1.3 \%, 8.1 \%, 22.7 \%$, $43.3 \%)$; the proportion of patients not receiving any antithrombotic therapy increased from C2 to C4 $(8.9 \%$,
$14.4 \%, 15.1 \%)$ then stayed similar in C5 $(15.7 \%)$. Co-prescription of AC and AP was variable (C2 14.0\%, C3 $11.8 \%$, C4 $11.4 \%$, C5 $11.7 \%$ ). Table 2 shows selected baseline characteristics for all patients (C2 to C5 combined) according to treatment group. Patients receiving no treatment generally had a lower incidence of comorbidities, apart from history of bleeding; however, patients aged $\geq 75$ years were more likely not to receive treatment.

Overall, $19.1 \%(666 / 3482)$ of patients were prescribed NOACs. Table 3 shows the baseline characteristics of patients on NOACs by cohort. There were no clear patterns of NOAC use by patient characteristics; however, patients diagnosed in cardiology in the earlier cohorts were more likely to be given NOACs than those in the later cohorts, while among patients diagnosed in primary care the later cohorts were more likely to receive NOACs than earlier cohorts. Of the patients prescribed either NOACs or VKA, those with dementia were significantly more likely to receive NOACs than VKA compared with patients without a history of the condition (table 4). Also, patients were more likely to receive NOACs over VKA as the cohorts progressed, from C2 to C5; however, no interaction between cohort and covariates was statistically significant.

Table 5 shows the baseline characteristics of patients who received no AC therapy $(34.3 \%, 1195 / 3482)$ by cohort. There were no clear changes over time in 'no AC' use when considering individual patient characteristics. Nevertheless, in the whole population, 'no AC' was less likely (relative to AC therapy) in patients aged 65-80 years, with diabetes, or a history of vascular disease and previous stroke/TIA/SE than in patients without these conditions or other age groups (table 6). 'No AC' was more likely if patients had a history of bleeding or with NSAID usage. Over time, UK physicians became increasingly less likely to choose 'no AC' with each successive cohort of patients enrolled between 2011 and 2016.

\section{Antithrombotic therapy use according to risk score}

Figure 2 shows the use of antithrombotic therapy according to $\mathrm{CHA}_{2} \mathrm{DS}_{2}$-VASc score and cohort. Notably, the registry includes a few patients classified as low risk according to the $\mathrm{CHA}_{2} \mathrm{DS}_{2}$-VASc score (ie, 0 for men, 1 for women) because the determination of risk factors was left to the clinician's judgement and not prespecified in the protocol. The use of $\mathrm{AC} \pm \mathrm{AP}$ increased from C2 to C4 for patients at all levels of stroke risk (low, moderate and high risk), though the increase was highest in patients with a $\mathrm{CHA}_{2} \mathrm{DS}_{2}$-VASc of $\geq 2$ (C2 $56.7 \%$; $4475.6 \%)$. At the same time, there was a decline in the proportion of patients receiving AP only and an increase in the proportion of high-risk patients not receiving any antithrombotic therapy. The overall use of antithrombotic therapy decreased in patients with low risk of stroke from $\mathrm{C} 2$ to $\mathrm{C} 4$, driven by a decline in the use of AP only from $35.7 \%$ in C2 to $11.8 \%$ in C4. 
Table 2 Baseline characteristics of patients in cohorts 2 to 5 by antithrombotic treatment type

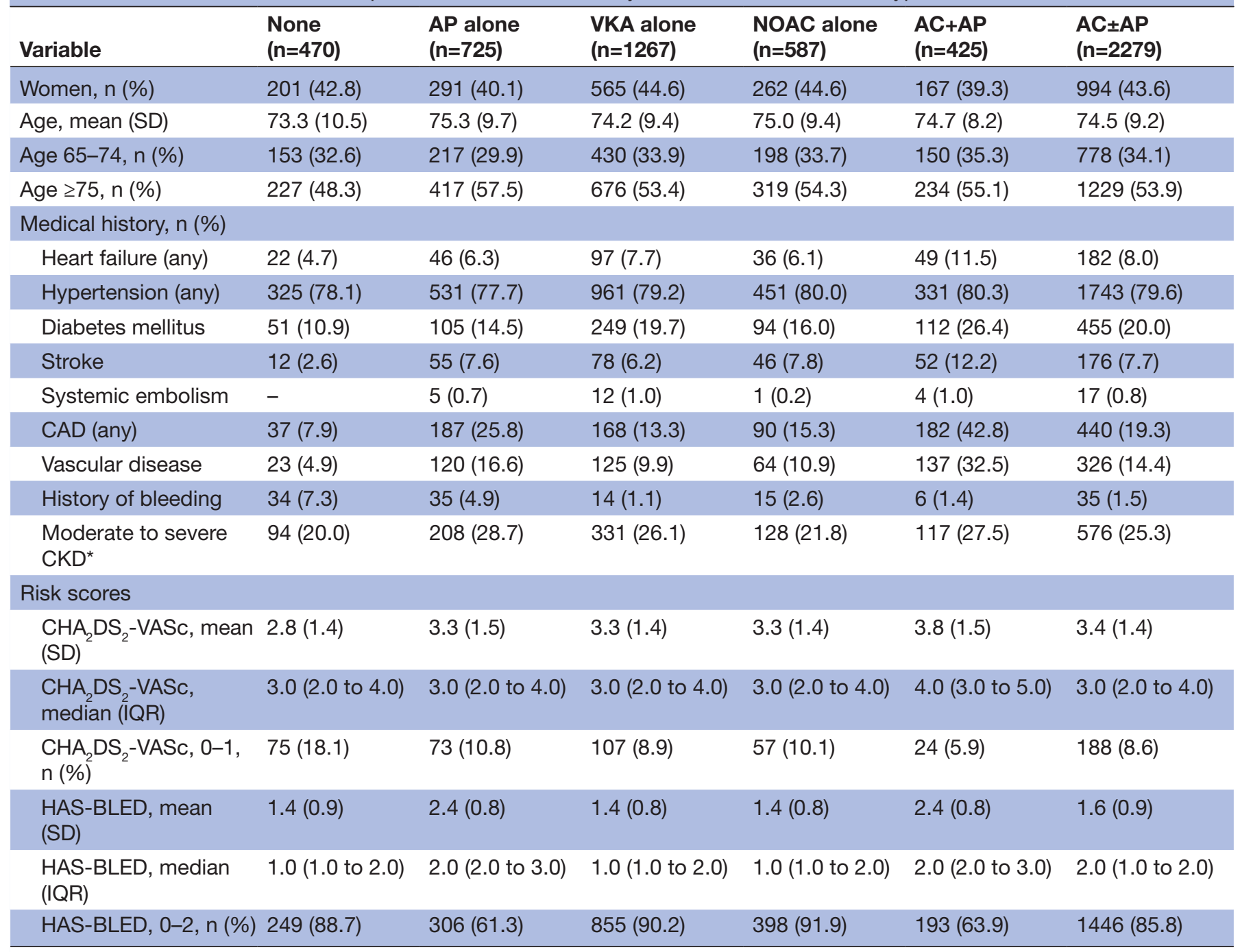

${ }^{*}$ Includes NKF KDOQI stages III-V.

$\mathrm{AC}$, anticoagulant; $\mathrm{AP}$, antiplatelet; $\mathrm{CAD}$, coronary artery disease; $\mathrm{CHA}_{2} \mathrm{DS}_{2}-\mathrm{VASc}$, cardiac failure, hypertension, age $\geq 75$ (doubled), diabetes, stroke (doubled)-vascular disease, age 65-74 and sex category (female); CKD, chronic kidney disease; HAS-BLED, hypertension, abnormal renal/liver function (1 point each), stroke, bleeding history or predisposition, elderly (>65), drugs/alcohol concomitantly (1 point each); NKF KDOQI, National Kidney Foundation's Kidney Disease Outcomes Quality Initiative; NOAC, non-vitamin K antagonist oral anticoagulant; VKA, vitamin $\mathrm{K}$ antagonist.

Also, the proportion of low-risk patients not receiving any antithrombotic therapy increased from $21.4 \%$ to $35.3 \%$. There was a slightly different pattern from $\mathrm{C} 4$ to $\mathrm{C} 5$; there was a decrease in the use of $\mathrm{AC} \pm \mathrm{AP}$ in patients at low risk (C4 53.0\%, C5 40.0\%) and C5 had the largest proportion of low-risk patients not receiving treatment $(50.0 \%)$. C5 saw an increase in NOAC use across all stroke risk levels, along with a decrease in the use of VKA.

Figure 3 shows the use of antithrombotic therapy according to HAS-BLED score and cohort. There was an increase in AC use over the study period for patients with a HAS-BLED score of 0 to 2; notably, there was a steady increase in $\mathrm{AC} \pm \mathrm{AP}$ use in patients with $\mathrm{HAS}-\mathrm{BLED} \geq 3$, peaking at C4 (C2 40.1\%, C3 46.7\%, C4 66.0\%, C5 58.2\%) at the expense of AP use.
Main reason anticoagulant was not used in patients with $\mathrm{CHA}_{2} \mathrm{DS}_{2}-\mathrm{VASC} \geq 2$

The main reasons why ACs were not used in patients with a $\mathrm{CHA}_{2} \mathrm{DS}_{2}$-VASc score of $\geq 2$ are shown in table 7 . The top two known reasons were patient refusal and physician's choice. Patient refusal was variable, and in the most recent cohort (C5), it accounted for $11.2 \%$ of high-risk patients not receiving AC. There were also some variations in the reasons for physicians choosing not to give high-risk patients ACs across the cohorts; the main reason in C2 was fall risk, whereas the main reason in C5 was bleeding risk.

\section{DISCUSSION}

These findings from the UK cohort of the GARFIELD-AF registry indicate a progressive improvement in the 
Table 3 Baseline characteristics of patients on NOACs by cohort

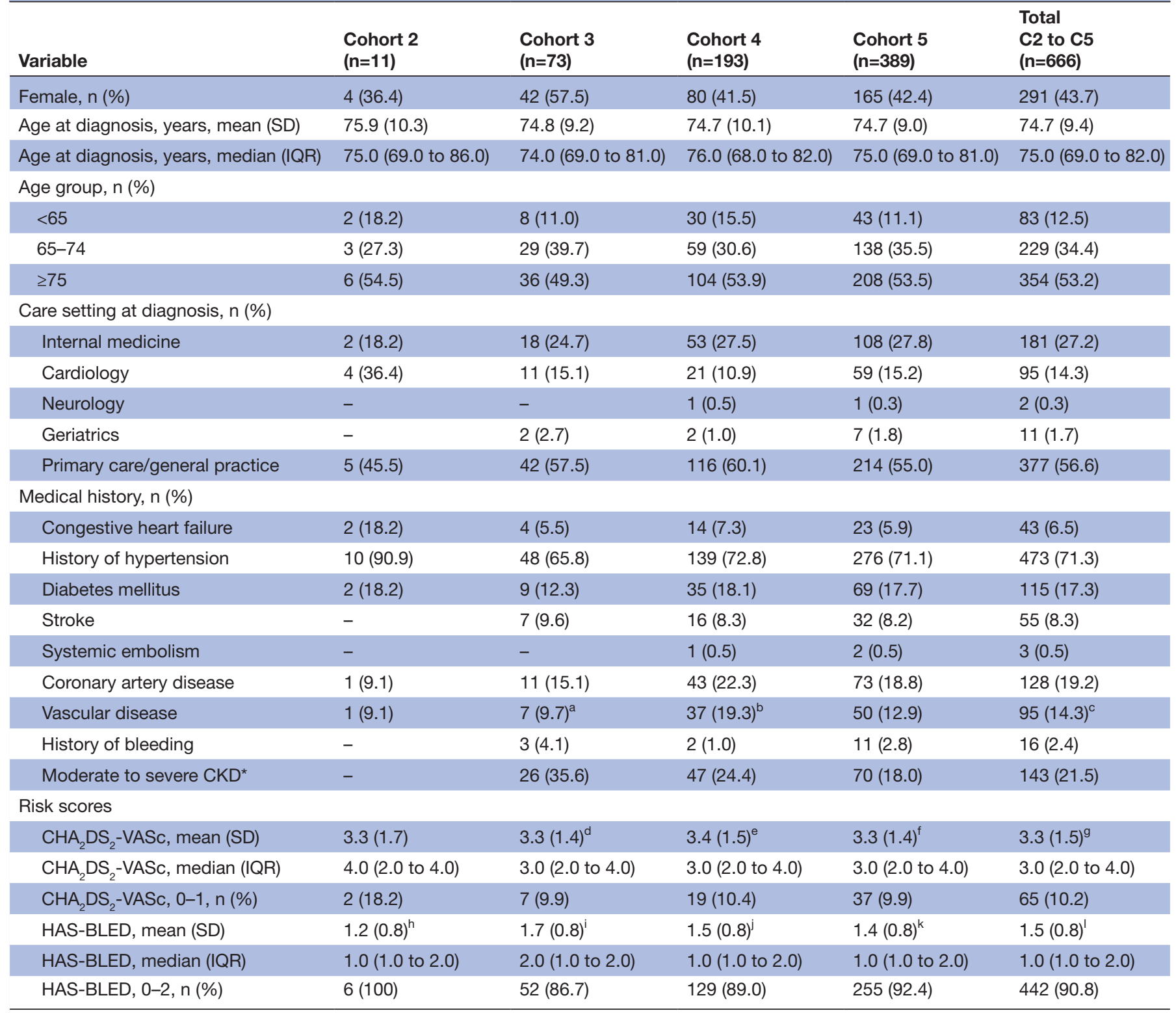

Patients missing: ${ }^{a} 1,{ }^{b} 1,{ }^{c} 2,{ }^{d} 2,{ }^{e} 10,{ }^{f} 16,{ }^{g} 28,{ }^{h} 5,{ }^{i} 13,{ }^{j} 48,{ }^{k} 113,{ }^{l} 179$.

${ }^{*}$ Includes NKF KDOQI stages III-V.

$\mathrm{CHA}_{2} \mathrm{DS}_{2}$-VASc, cardiac failure, hypertension, age $\geq 75$ (doubled), diabetes, stroke (doubled)-vascular disease, age 65-74 and sex category (female); CKD, chronic kidney disease; HAS-BLED, hypertension, abnormal renal/liver function (1 point each), stroke, bleeding history or predisposition, elderly (>65), drugs/alcohol concomitantly (1 point each); NKF KDOQI, National Kidney Foundation's Kidney Disease Outcomes Quality Initiative; NOAC, non-vitamin K antagonist oral anticoagulant.

clinical management of $\mathrm{AF}$, with newly diagnosed at-risk patients with AF more often receiving guideline-recommended therapy. The proportion of patients on AC increased (C2 54.5\%, C3 60.1\%, C4 72.9\%, C5 73.9\%) and the increase in the use of AC was mainly in patients with $\mathrm{CHA}_{2} \mathrm{DS}_{2}-\mathrm{VASc} \geq 2$. There was a notable increase in the use of NOACs \pm AP (C2 1.3\%, C3 $8.0 \%$, C4 23.0\%, C5 $43.3 \%$ ), with the main increase in NOAC prescribing being driven by the prescribing of factor Xa inhibitors; C5 saw a change in VKA prescribing, with NOACs being prescribed in place of VKA. The use of AP only decreased (C2 36.5\%, C3 25.3\%, C4 11.9\%, C5 10.5\%); however, the co-prescription of AC+AP did not change much (C2 14\%, C3 11.8\%, C4 11.4\%, C5 11.7\%). AC use decreased with bleeding risk, with people with HAS-BLED $\geq 3$ less likely to be anticoagulated; nevertheless, use of $\mathrm{AC}$ in patients with HAS-BLED $\geq 3$ increased notably from $40.1 \%$ in C2 to the peak of $66.0 \%$ in $\mathrm{C} 4$.

In addition, there was a decline in AP use in patients at low risk, with a corresponding increase in the proportion of patients in this category not receiving any antithrombotic therapy. However, an important proportion of low-risk patients received AC over the period, with $50 \%$ of low-risk patients receiving $\mathrm{AC}$ in the most recent cohort. 
Table 4 Use of NOACs in relation to baseline characteristics for patients on an AC at baseline

\begin{tabular}{|c|c|}
\hline Variable & $\begin{array}{l}\text { Cohorts } 2 \text { to } 5 \\
\text { OR }(95 \% \mathrm{Cl})\end{array}$ \\
\hline \multicolumn{2}{|l|}{ Gender } \\
\hline Female & 1 \\
\hline Male & 0.90 (0.72 to 1.12$)$ \\
\hline \multicolumn{2}{|l|}{ Age (years) } \\
\hline 65 & 1 \\
\hline $65-80$ & 0.66 (0.47 to 0.92$)$ \\
\hline 80-85 & 0.71 (0.48 to 1.07$)$ \\
\hline$>85$ & 1.02 (0.66 to 1.59$)$ \\
\hline \multicolumn{2}{|l|}{ Medical history* } \\
\hline Congestive heart failure & 0.88 (0.58 to 1.34$)$ \\
\hline $\begin{array}{l}\text { Hypertension (history } \\
\text { or >140/90 mm Hg) }\end{array}$ & 1.23 (0.93 to 1.62$)$ \\
\hline Diabetes & 0.78 (0.59 to 1.02$)$ \\
\hline Coronary artery disease & 1.14 (0.80 to 1.65$)$ \\
\hline Vascular disease & $1.14(0.76$ to 1.71$)$ \\
\hline Dementia & 3.58 (1.15 to 11.15$)$ \\
\hline Moderate to severe CKD† & 0.85 (0.65 to 1.10$)$ \\
\hline NSAID usage & $0.57(0.44$ to 0.74$)$ \\
\hline Bleeding & 1.90 (0.86 to 4.19$)$ \\
\hline Previous stroke/TIA/SE & 1.29 (0.96 to 1.75$)$ \\
\hline \multicolumn{2}{|l|}{ Smoking } \\
\hline Never & 1 \\
\hline Ex-smoker & 1.03 (0.82 to 1.29$)$ \\
\hline Current smoker & 0.61 (0.38 to 0.97$)$ \\
\hline \multicolumn{2}{|l|}{ Cohort } \\
\hline 2 & 1 \\
\hline 3 & 6.14 (3.28 to 11.52$)$ \\
\hline 4 & 7.24 (9.43 to 31.53$)$ \\
\hline 5 & 55.21 (30.29 to 100.62$)$ \\
\hline
\end{tabular}

${ }^{*}$ Reference group is patients with no history of disease (for congestive heart failure, hypertension, diabetes, coronary artery disease, vascular disease, dementia, moderate to severe CKD, NSAID usage, bleeding, previous stroke/TIA/SE).

†Includes NKF KDOQI stages III-V; none or mild (reference group) includes all other patients.

An OR $>1$ implies that NOACs are more frequent than VKAs, while an $\mathrm{OR}<1$ means that VKAs are more frequent than NOACs. No interaction between cohort and covariates was statistically significant.

AC, anticoagulant; CKD, chronic kidney disease; NKF KDOQI, National Kidney Foundation's Kidney Disease Outcomes Quality Initiative; NOAC, non-vitamin K antagonist oral anticoagulant; NSAID, non-steroidal anti-inflammatory drug; SE, systemic embolism; TIA, transient ischaemic attack; VKA, vitamin $\mathrm{K}$ antagonist.

For patients with a $\mathrm{CHA}_{2} \mathrm{DS}_{2}$-VASc score of 1 , there was a notable increase in $\mathrm{AC}$ prescribing from $\mathrm{C} 2$ to $\mathrm{C} 5$ and a steep decline in the use of AP only.
Our findings are, to a large extent, consistent with changes in AF management guidelines. In the UK, NICE guidelines up until 2014 recommend that high-risk patients should be on warfarin, those at moderate risk should receive warfarin or aspirin, and low-risk patients should not be on warfarin (but could be prescribed aspirin). ${ }^{17}$ The current (2014) guidelines no longer recommend aspirin; patients should receive anticoagulation or not. ${ }^{5}$ The notable increase in AC use and corresponding decline in AP use fall within the guidelines; our data suggest patients that would have been given aspirin in earlier cohorts are now given $\mathrm{AC}$, also that the increase in $\mathrm{AC}$ use is potentially driven by the availability of NOACs.

This is the first UK study to describe the reasons for not anticoagulating real-world patients in relation to stroke risk, and the findings corroborate our deduction that guidelines have influenced clinical practice. The data suggest that patient refusal (11.2\% for high-risk patients in the most recent cohort) may be the main patient factor affecting rates of anticoagulation. There is little UK evidence on AC treatment rates in the post-VKA-only era; nevertheless, co-prescription of ACs and APs (15.1\%) is higher than reported by Kassianos et $a l^{11}$ ( $11 \%$ initiated on ACs plus APs within 12 weeks of diagnosis of AF).

\section{Strengths and limitations}

This study describes real-world clinical practice in the UK for treatment initiated at $\mathrm{AF}$ diagnosis in patients with $\mathrm{AF}$ and at least one risk factor for stroke. Recruiting patients from primary care captures patients regardless of the care setting of diagnosis, therefore providing a pool of patients representative of UK patients diagnosed with AF. Study sites sought to recruit consecutive eligible patients, thereby reducing the risk of selection bias. In addition, the 6-week period between diagnosis and enrolment minimises the risk of excluding deceased patients.

The study is subject to the limitations inherent to observational studies, although efforts were made to standardise definitions and reduce missing data. Ethical approval for the study does not cover patients without the capacity to consent. The data on low-risk patients need to be interpreted with caution due to the low numbers in the UK sample. Comorbidities are likely confounders in treatment strategies; however, these were not comprehensively incorporated in this analysis.

\section{Comparison with global GARFIELD-AF data}

Evolving antithrombotic treatment patterns up to C4 for the global GARFIELD-AF population have previously been published ${ }^{18}$; our comparison is in relation to UK patients enrolled during the corresponding recruitment period (C2 to C4). Globally, a total of 34170 patients were enrolled into C2 to $\mathrm{C} 4$ in 34 countries. UK patients were older than patients in the global study: mean age of 74.7 years compared with 69.9 years in the global study. ${ }^{18}$ UK patients had less heart failure ( $7.6 \%$ vs $19.8 \%)$, higher prevalence of CKD (26.5\% vs $10.3 \%$ ), but similar rates of 
Table 5 Baseline characteristics of patients not on AC by cohort

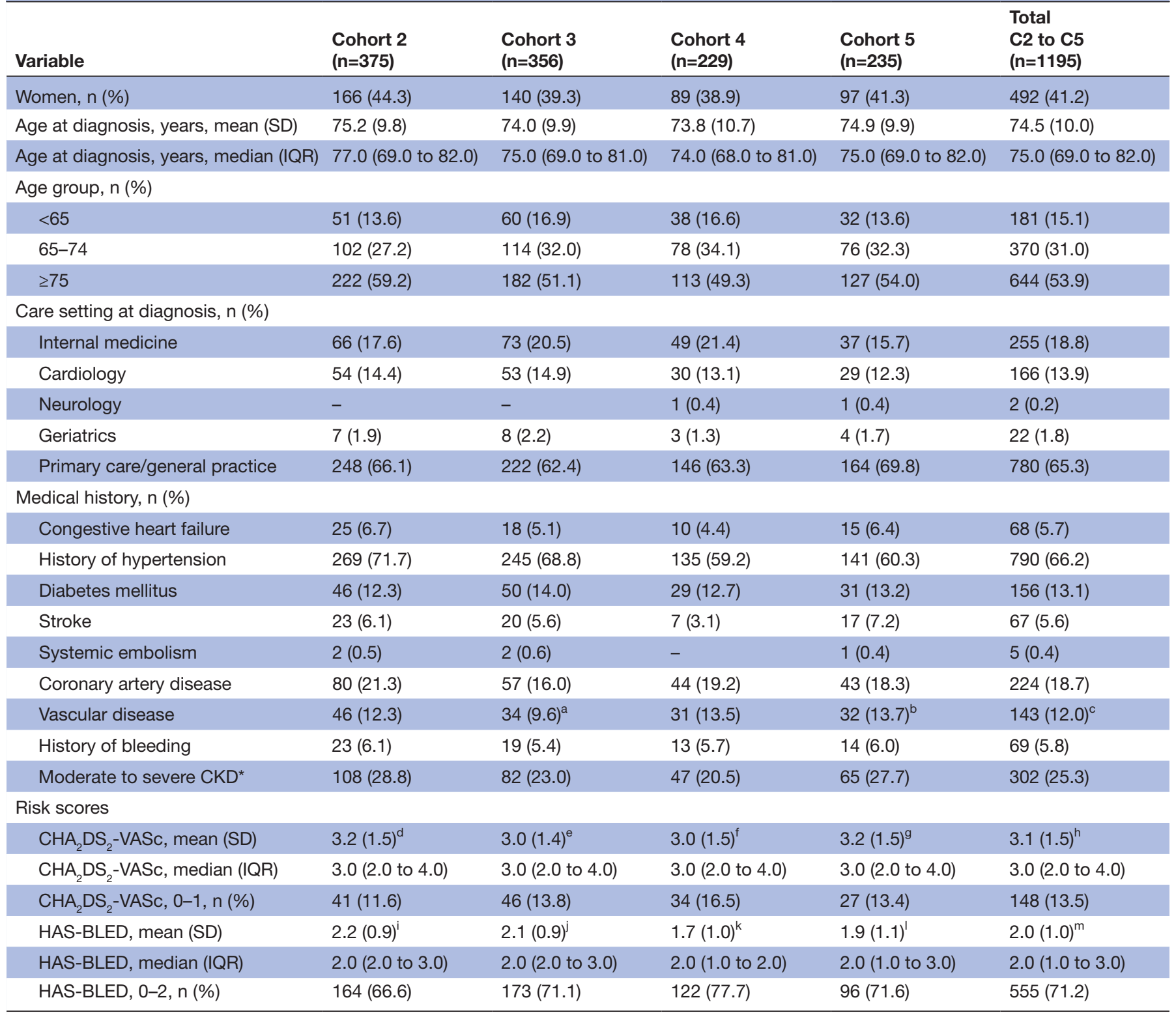

Patients missing: ${ }^{\mathrm{a}} 1,{ }^{\mathrm{b}} 1,{ }^{\mathrm{c}} 2,{ }^{\mathrm{d}} 22,{ }^{\mathrm{e}} 24,{ }^{\mathrm{f}} 22,{ }^{\mathrm{g}} 34,{ }^{\mathrm{h}} 102,{ }^{\mathrm{i}} 129,{ }^{\mathrm{i}} 113,{ }^{\mathrm{k}} 72,{ }^{\mathrm{l}} 101,{ }^{\mathrm{m}} 415$.

*Includes NKF KDOQI stages III-V.

$\mathrm{AC}$, anticoagulant; $\mathrm{CHA}_{2} \mathrm{DS}_{2}-\mathrm{VASc}$, cardiac failure, hypertension, age $\geq 75$ (doubled), diabetes, stroke (doubled)-vascular disease, age 65-74 and sex category (female); CKD, chronic kidney disease; HAS-BLED, hypertension, abnormal renal/liver function (1 point each), stroke, bleeding history or predisposition, elderly (>65), drugs/alcohol concomitantly (1 point each), NKF KDOQI, National Kidney Foundation's Kidney Disease Outcomes Quality Initiative.

coronary artery disease and acute coronary syndromes. UK patients had a higher proportion of those with $\mathrm{CHA}_{2} \mathrm{DS}_{2}$-VASc score of $0-1(10.5 \%$ vs $14.7 \%)$ and a lower proportion with HAS-BLED of $0-2(81.3 \%$ vs $88.7 \%)$.

Despite starting from a lower baseline, the use of $\mathrm{AC}$ in the UK in the most recent cohort is comparable to that in the global study (UK $54.7 \%$ to $73.1 \%$, global $62.1 \%$ to $71.1 \%) .{ }^{18}$ Nevertheless, the uptake of NOACs is higher in the global study, with NOACs being prescribed in place of VKA, whereas VKA prescribing in the UK hardly changed up until C4 (NOAC use in C4: global $37.2 \%$, UK 22.7\%). In C5, however, UK data illustrate a decline in VKA prescribing matched by an increase in NOAC use. As in the UK population, overtreatment of patients at low risk of stroke was observed in the global population, and over $50 \%$ of low-risk patients in C4 received AC. This may be due to clinicians' perception of stroke risk as all participants were deemed by the recruiting clinician to have an investigator-determined risk factor for stroke. Co-prescription of $\mathrm{AC}+\mathrm{AP}$ was also an issue in the global population, with $6.8 \%$ affected in $\mathrm{C} 4$; however, the UK seems to have responded better to the renunciation of AP only as a treatment option: in C4, $11.7 \%$ of high-risk UK patients were given AP only compared with $16.0 \%$ in the global population. 
Table 6 Use of antiplatelet and no treatment (no AC) versus anticoagulant in relation to baseline characteristics

\begin{tabular}{|c|c|}
\hline Variable & $\begin{array}{l}\text { Cohorts } 2 \text { to } 5 \\
\text { OR }(95 \% \mathrm{Cl})\end{array}$ \\
\hline \multicolumn{2}{|l|}{ Gender } \\
\hline Female & 1 \\
\hline Male & 1.09 (0.91 to 1.30$)$ \\
\hline \multicolumn{2}{|l|}{ Age (years) } \\
\hline$<65$ & 1 \\
\hline $65-80$ & 0.70 (0.54 to 0.90$)$ \\
\hline $80-85$ & 0.75 (0.55 to 1.02$)$ \\
\hline$>85$ & 0.98 (0.70 to 1.36$)$ \\
\hline \multicolumn{2}{|l|}{ Medical history* } \\
\hline Congestive heart failure & 0.73 (0.52 to 1.03$)$ \\
\hline $\begin{array}{l}\text { Hypertension (history or } \\
>140 / 90 \mathrm{~mm} \mathrm{Hg} \text { ) }\end{array}$ & 0.89 (0.72 to 1.09$)$ \\
\hline Diabetes & 0.57 (0.45 to 0.72$)$ \\
\hline Coronary artery disease & 0.84 (0.64 to 1.11$)$ \\
\hline Vascular disease & 0.63 (0.46 to 0.87$)$ \\
\hline Dementia & 0.72 (0.28 to 1.84$)$ \\
\hline Moderate to severe CKD $†$ & $0.92(0.75$ to 1.12$)$ \\
\hline NSAID usage & 5.85 (4.89 to 7.00$)$ \\
\hline Bleeding & 6.30 (3.90 to 10.18$)$ \\
\hline Previous stroke/TIA/SE & 0.47 (0.36 to 0.62$)$ \\
\hline \multicolumn{2}{|l|}{ Smoking } \\
\hline Never & 1 \\
\hline Ex-smoker & $0.96(0.81$ to 1.15$)$ \\
\hline Current smoker & 1.04 (0.73 to 1.48$)$ \\
\hline \multicolumn{2}{|l|}{ Cohort } \\
\hline 2 & 1 \\
\hline 3 & 0.84 (0.67 to 1.05$)$ \\
\hline 4 & 0.55 ( 0.43 to 0.70$)$ \\
\hline 5 & 0.52 (0.41 to 0.66$)$ \\
\hline
\end{tabular}

${ }^{*}$ Reference group is patients with no history of disease (for congestive heart failure, hypertension , diabetes, coronary artery disease, vascular disease, dementia, moderate to severe CKD, NSAID usage, bleeding, previous stroke/TIA/SE) †Includes NKF KDOQI stages III-V; none or mild (reference group) includes all other patients.

Please note: An OR $>1$ implies that No ACs are more frequent than $A C s$, while an $O R<1$ means that $A C s$ are more frequent than No ACs. Odds ratios were adjusted for all variables in the model. AC, anticoagulant; CKD, chronic kidney disease; NKF KDOQI, National Kidney Foundation's Kidney Disease Outcomes Quality Initiative; NSAID, non-steroidal anti-inflammatory drug; SE, systemic embolism; TIA, transient ischaemic attack.

\section{Implications for practice}

These data indicate progressive concordance with evidence-based guidelines and clinical practice in the UK for patients newly diagnosed with AF. More UK patients are receiving guideline-recommended therapy; this is significant, given the increasing prevalence of $\mathrm{AF}$ in the

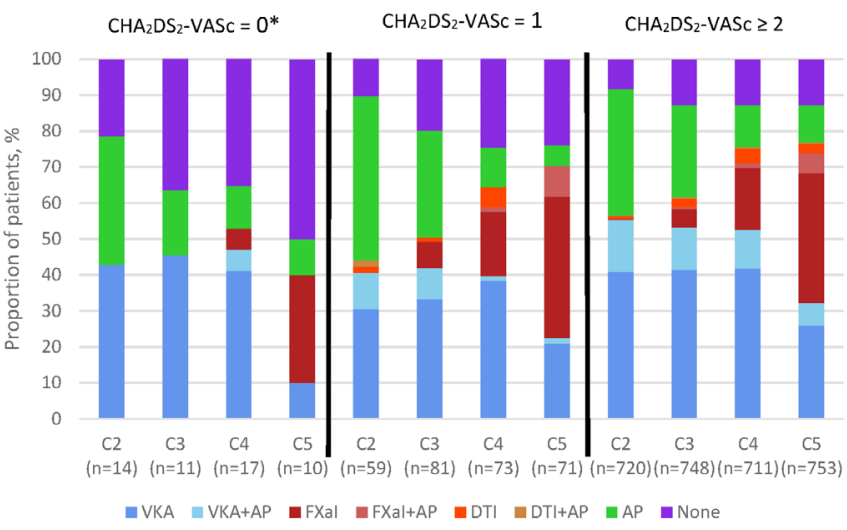

Figure 2 Antithrombotic treatment at diagnosis by $\mathrm{CHA}_{2} \mathrm{DS}_{2}-\mathrm{VASc}$ and cohort, for patients with a score of 0,1 and $\geq 2$. ${ }^{*}$ Includes women with no other risk factors. The total population represented by $n$ excludes unknowns. Patients with missing $\mathrm{CHA}_{2} \mathrm{DS}_{2}$-VASc score: C2, 35; C3, 58; C4, 49; $\mathrm{C} 5,65$. AP, antiplatelet; $\mathrm{CHA}_{2} \mathrm{DS}_{2}-\mathrm{VASc}$, cardiac failure, hypertension, age $\geq 75$ (doubled), diabetes, stroke (doubled)vascular disease, age 65-74 and sex category (female); DTI, direct thrombin inhibitor; FXal, factor Xa inhibitor; VKA, vitamin $\mathrm{K}$ antagonist.

UK. Although the proportion of high-risk patients taking an AC in the most recent cohort is unprecedented, nearly a quarter of high-risk patients still do not receive AC therapy, indicating that there is further scope for improvement. It is important to elucidate the reasons why some high-risk patients do not receive anticoagulation; in particular, the reasons and circumstances for patient refusal need to be explored (and documented). An important proportion of low-risk patients are still receiving $\mathrm{AC}$ despite the proven capability of the $\mathrm{CHA}_{2} \mathrm{DS}_{2}$-VASc score to identify patients at truly low risk. Further attention to

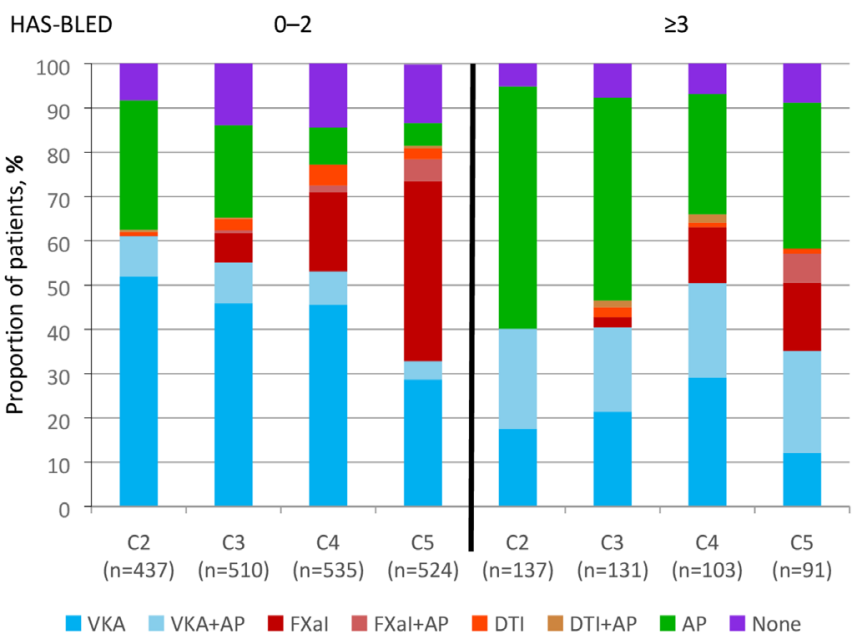

Figure 3 Antithrombotic treatment at diagnosis by HASBLED score and cohort, for patients with a score of 0-2 and $\geq 3$. AP, antiplatelet; DTI, direct thrombin inhibitor; FXal, factor Xa inhibitor; HAS-BLED, hypertension, abnormal renal/liver function (1 point each), stroke, bleeding history or predisposition, elderly (>65), drugs/alcohol concomitantly (1 point each); VKA, vitamin $\mathrm{K}$ antagonist. 
Table 7 Main reason anticoagulant not used in patients with $\mathrm{CHA}_{2} \mathrm{DS}_{2}-\mathrm{VASc} \geq 2$

\begin{tabular}{lllll}
\hline Variable & $\begin{array}{l}\text { Cohort 2 } \\
\mathbf{( n = 3 0 7 )} \\
\mathbf{n} \%\end{array}$ & $\begin{array}{l}\text { Cohort 3 } \\
\mathbf{( n = 2 7 9 )} \\
\mathbf{n} \%\end{array}$ & $\begin{array}{l}\text { Cohort 4 } \\
\mathbf{( n = 1 7 1 )} \\
\mathbf{n} \%\end{array}$ & $\begin{array}{l}\text { Cohort 5 } \\
\mathbf{( n = 1 7 0 )} \\
\mathbf{n} \%\end{array}$ \\
\hline $\begin{array}{l}\text { Main reason anticoagulant not used } \\
\text { Already taking antiplatelet drugs for other medical } \\
\text { condition }\end{array}$ & $30(9.8)$ & $11(3.9)$ & $5(2.9)$ & $9(5.3)$ \\
\hline $\begin{array}{l}\text { Patient refusal } \\
\text { Previous bleeding event }\end{array}$ & $44(14.3)$ & $51(18.3)$ & $24(14.0)$ & $19(11.2)$ \\
\hline $\begin{array}{l}\text { Taking medication contraindicated or cautioned for use } \\
\text { with VKA or AC }\end{array}$ & $6(2.0)$ & $5(1.8)$ & $7(4.1)$ & $5(2.9)$ \\
\hline $\begin{array}{l}\text { Other } \\
\text { Unknown }\end{array}$ & $113(36.8)$ & $100(35.8)$ & $73(42.7)$ & $79(46.5)$ \\
\hline $\begin{array}{l}\text { Physician's choice† } \\
\quad \text { Bleeding risk }\end{array}$ & $70(22.8)$ & $72(25.8)$ & $46(26.9)$ & $36(21.2)$ \\
$\quad$ Concern over patient compliance & $43(14.0)$ & $38(13.6)$ & $15(8.8)$ & $20(11.8)$ \\
$\quad$ Guideline recommendation & $8(18.6)$ & $10(26.3)$ & $9(60.0)$ & $13(65.0)$ \\
\hline $\begin{array}{l}\text { Fall risk } \\
\text { Low risk of stroke }\end{array}$ & $3(7.0)$ & $1(2.6)$ & - & - \\
\hline
\end{tabular}

*Percentages are calculated with the column ' $n$ ' as denominator;

†Percentages in each category of the physician's choice are calculated with the available (non-missing) data of the variable as denominator. AC, anticoagulant; $\mathrm{CHA}_{2} \mathrm{DS}_{2}$-VASc, cardiac failure, hypertension, age $\geq 75$ (doubled), diabetes, stroke (doubled)-vascular disease, age 6574 and sex category (female); VKA, vitamin K antagonist.

patients in this category will be beneficial. Also, patients are being co-prescribed ACs and aspirin (11.7\% of highrisk patients in most recent cohort), a combination that is rarely indicated since it increases bleeding risk by over $50 \%$; it might be worth exploring the rationale for this in future research.

The clinical management of patients with $\mathrm{AF}$ is evolving and treatment outcomes will become clearer with time. GARFIELD-AF provides real-world data on evolving treatment patterns, and further data will provide insight into corresponding treatment outcomes.

Acknowledgements We thank the physicians, nurses and patients involved in the GARFIELD-AF registry. SAS programming support was provided by Madhusudana Rao (Thrombosis Research Institute, London, UK). Editorial support was provided by Emily Chu (Thrombosis Research Institute, London, UK). FDRH acknowledges part-funding from the NIHRSchool for Primary Care Research, NIHR CLARHC Oxford, NIHR Oxford BRC, and NIHROxford DEC.

Collaborators A full list of the UK GARFIELD-AF Investigators is given in the online supplementary appendix 1 .

Contributors PNA contributed to the acquisition, analysis and interpretation of data for the study, and drafted the manuscript. HG contributed to the analysis and interpretation of the data and revised the work critically for intellectual content. FDRH contributed to the interpretation of the data and revised the work critically for intellectual content. DAF contributed to the acquisition, analysis and interpretation of the data and revised the work critically for intellectual content. FDRH and DAF contributed to the initial methods of GARFIELD-AF in the UK. DAF is also the Principal Investigator and guarantor for the UK study. All authors approved the final version of the manuscript and are accountable for all aspects of the work.

Funding The GARFIELD-AF registry is sponsored by the Thrombosis Research Institute, London, UK. Funding of the registry is provided through an educational research grant from Bayer AG (Berlin, Germany).
Competing interests FDRH personal fees and other from BMS/Pfizer, personal fees and other from BI, personal fees and other from Bayer, outside the submitted work.

Patient consent Obtained.

Ethics approval The UK has received ethical approval from the South East London Research Ethics Committee 5 (REC 5) on 29 September 2010; REC reference 10/ H0805/48.

Provenance and peer review Not commissioned; externally peer reviewed. Data sharing statement № additional data available.

Open Access This is an Open Access article distributed in accordance with the Creative Commons Attribution Non Commercial (CC BY-NC 4.0) license, which permits others to distribute, remix, adapt, build upon this work non-commercially, and license their derivative works on different terms, provided the original work is properly cited and the use is non-commercial. See: http://creativecommons.org/ licenses/by-nc/4.0/

(c) Article author(s) (or their employer(s) unless otherwise stated in the text of the article) 2018. All rights reserved. No commercial use is permitted unless otherwise expressly granted.

\section{REFERENCES}

1. Wolf PA, Abbott RD, Kannel WB. Atrial fibrillation as an independent risk factor for stroke: the Framingham Study. Stroke 1991;22:983-8.

2. Wolf PA, Abbott RD, Kannel WB. Atrial fibrillation: a major contributor to stroke in the elderly. The Framingham Study. Arch Intern Med 1987;147:1561-4.

3. Jørgensen HS, Nakayama $\mathrm{H}$, Reith J, et al. Acute stroke with atrial fibrillation. The Copenhagen Stroke Study. Stroke 1996;27:1765-9.

4. Camm AJ, Kirchhof P, Lip GY, et al. Guidelines for the management of atrial fibrillation: the Task Force for the Management of Atrial Fibrillation of the European Society of Cardiology (ESC). Eur Heart $J$ 2010;31:2369-429.

5. National Instisute for Health and Clinical Excellence (NICE). Nice Clinical Guideline 180; Atrial Fibrillation: the management of atrial fibrillation. 2014 https://www.nice.org.uk/guidance/cg180 
6. Ogilvie IM, Newton N, Welner SA, et al. Underuse of oral anticoagulants in atrial fibrillation: a systematic review. Am J Med 2010;123:638-45.

7. Baczek VL, Chen WT, Kluger J, et al. Predictors of warfarin use in atrial fibrillation in the United States: a systematic review and metaanalysis. BMC Fam Pract 2012;13:5.

8. Mohammed MA, Marshall T, Nirantharakumar K, et al. Patterns of warfarin use in subgroups of patients with atrial fibrillation: a crosssectional analysis of 430 general practices in the United Kingdom. PLoS One 2013;8:e61979.

9. Holt TA, Hunter TD, Gunnarsson C, et al. Risk of stroke and oral anticoagulant use in atrial fibrillation: a cross-sectional survey. $\mathrm{Br} J$ Gen Pract 2012;62:710-7.

10. Cowan C, Healicon R, Robson I, et al. The use of anticoagulants in the management of atrial fibrillation among general practices in England. Heart 2013;99:1166-72.

11. Kassianos G, Arden C, Hogan S, et al. Current management of atrial fibrillation: an observational study in NHS primary care. BMJ Open 2013;3:e003004.

12. Kakkar AK, Mueller I, Bassand J-P, et al. International longitudinal registry of patients with atrial fibrillation at risk of stroke: Global
Anticoagulant Registry in the FIELD (GARFIELD). Am Heart J 2012;163:13-19.

13. Apenteng PN, Murray ET, Holder R, et al. An international longitudina registry of patients with atrial fibrillation at risk of stroke (GARFIELD): the UK protocol. BMC Cardiovasc Disord 2013;13:31.

14. National Kidney Foundation. K/DOQI clinical practice guidelines for chronic kidney disease: evaluation, classification, and stratification. Am J Kidney Dis 2002;39(2 Suppl 1):S1.

15. van Buuren S. Multiple imputation of discrete and continuous data by fully conditional specification. Stat Methods Med Res 2007;16:219-42.

16. Raghunathan TE, Lepkowski JM, Van Hoewyk J, et al. A multivariate technique for multiply imputing missing values using a sequence of regression models. Survey Methodology 2001;27:85-96.

17. National Instisute for Health and Clinical Excellence (NICE). Clinical Guideline CG36-Atrial Fibrillation: the management of atrial fibrillation. 2006 http://www.nice.org.uk/CG36.

18. Camm AJ, Accetta G, Ambrosio G, et al. Evolving antithrombotic treatment patterns for patients with newly diagnosed atrial fibrillation. Heart 2017;103:307-14. 